\title{
ПУТИ КАЧЕСТВЕННОГО ПОВЫШЕНИЯ ТРУДОВЫХ РЕСУРСОВ В ИННОВАЦИОННЫХ УСЛОВИЯХ ЭКОНОМИКИ
}

\author{
Иионкулова Феруза Асатовна \\ Стариий преподаватель \\ Самаркандского института экономики и сервис \\ Узбекистан \\ Узаков Элдор \\ Студент 1 курса \\ Самаркандского института экономики и сервиса \\ Узбекистан.
}

\begin{abstract}
Аннотация. В статье исследуется зарубежный опыт обеспечения занятости населения с целью достижения макроэкономической стабильности в стране и даются рекомендации на основе исследования.

Ключевые слова: экономика, социальная защита, занятость, трудовые договоры, трудовой опыт, факторы, безработица, рабочие навыки, рабочая сила.
\end{abstract}

Одна из важных задач для достижения макроэкономической стабильности в Республике Узбекистан обеспечение занятости населения. В частности, увеличение количества рабочих мест и рост занятости позволяют оценивать ситуацию как важный индикатор этого процесса.

Это требует теоретического наблюдения за новыми тенденциями, определяющими состав занятости, всестороннего изучения факторов, влияющих на функционирование рынка труда. В связи с этим Президент Республики Узбекистан Ш.Мирзиёев отметил, что «Увеличение доходов населения, создает дополнительные рабочие места, увеличивает производство, многие законы и постановления соответствуют требованиям рыночной экономики и времени. "Несмотря на его принятие, приоритеты по повышению качества занятости пока не реализованы. Так, как пандемия COVID-19 на долгие месяцы повысила уровень безработицы не только в Узбекистане и во всём мире. Численность безработных за 2020 год в мире превысила 500 млн человек, а в нашей стране превысила 1млн 400 тысяч человек, в процентах составило 14-15\%

Из экономической литературы известно, что «занятое население» означает лиц, нанятых на основании письменного трудового договора или устного соглашения, а также самозанятых работодателей, членов фермерских хозяйств или компаний, индивидуальных предпринимателей, семьи. трудоспособное население, занятое трудом или надомным трудом. Таким образом, рабочая сила в нашей стране - это трудоспособные мужчины (от 16 до 60 лет) и женщины (от 16 до 55 лет) трудоспособного возраста.

В научно-экономических исследованиях основное внимание уделяется занятости, ее социальноэкономическому значению, классификации форм занятости, основным типам и формам занятости, трудовой миграции, регулированию занятости, распределению занятости по секторам экономики.

Среди ведущих ученых, проводивших исследования по определению теоретической основы проблем в этой области в стране, - Х.Абдурахманов, Х.П.Абулкасимов, Б.Х.Умурзаков, Ш.Р.Холмуминов, Д.Рахимова, Н.К.Зокирова, Д.А.Ортикова, Н.Рахимова, Р.Убайдуллаева , Н.Т.Шоюсупова. В их научной работе теоретически и практически изучался вопрос повышения занятости населения. При этом в результате исследования недостаточно внимания уделялось структуре занятости населения в научной работе отечественных и зарубежных ученых и практиков, что позволило бы правильно определить актуальность темы исследования, ее цели и задачи.

В сегодняшней рыночной экономике государству необходимо регулировать трудовые отношения, условия труда и заработную плату, компенсировать потерю заработной платы из-за различных рисков, обеспечивать правовую защиту работников. Углубление процесса общественного разделения труда привело к появлению новых независимых отраслей, в которых определенные производственные операции в сельском хозяйстве связаны с переработкой сельскохозяйственной продукции.

В связи с этим рабочая сила, используемая в сельском хозяйстве, перераспределяется в другие отрасли. Предприниматели и потребители больше не получают оборудование и некоторые потребительские товары от сельского хозяйства, а напрямую от тех отраслей, которые производят эти машины и потребительские товары.

Спрос на сельхозпродукцию вырастет до определенного уровня, а затем остановится. Например, спрос на фрукты и овощи и спрос на пшеницу будет увеличиваться по мере увеличения доходов, но динамика роста будет снижаться. Такие товары называют «товарами, отвечающими жизненным потребностям». Как только люди удовлетворяют свои жизненные потребности, они прекращают спрос на жизненно важные товары и увеличивают спрос на новые ценные продукты и услуги (автомобили, туризм и т. Д.). В результате в традиционных отраслях (сельское хозяйство) производители сталкиваются с остановкой роста спроса и начинают получать прибыль за счет снижения затрат. В результате, например, в аграрном секторе произойдет механизация трудового процесса, и из сельского хозяйства будет вытеснена дополнительная рабочая сила. Это, в свою очередь, приведет к 
увеличению производительности труда в сельском хозяйстве и уменьшению численности занятых в сельском хозяйстве.

С 1930 по 1960 год количество сельскохозяйственных рабочих в США сократилось в 2,7 раза, с 4,3 миллиона до 1,6 миллиона. С 1960 по 1985 год он сократился в 1,8 раза, с 1,6 миллиона до 0,9 миллиона. В Японии количество занятых в семейных фермерских хозяйствах в 1986 году сократилось в 3,8 раза - с 8,3 миллиона до 2,4 миллиона (таблица 1). Перераспределение рабочей силы не происходит только тогда, когда рабочая сила сохраняется в сельском хозяйстве или других областях. Не исключено, что такое перераспределение произойдет во всех случаях, независимо от площади.

Анализ показывает, что если количество работников в обрабатывающем секторе сокращается, занятость в сфере услуг увеличится (Таблица 1).

Таблица 1

По секторам занятости в развитых странах структура, \% (2017 г) ${ }^{1}$.

\begin{tabular}{|c|c|c|c|c|c|c|}
\hline Страны и регионы & $\begin{array}{c}\text { Общая } \\
\text { занятость }\end{array}$ & $\begin{array}{l}\text { Сельское } \\
\text { хозяйство }\end{array}$ & Промышленность & $\begin{array}{c}\text { Строительство, } \\
\text { транспорт и } \\
\text { связь }\end{array}$ & $\begin{array}{c}\text { Торговля, } \\
\text { общественное } \\
\text { питание, финансы, } \\
\text { жилищно- } \\
\text { коммунальные } \\
\text { услуги } \\
\text { экономия } \\
\end{array}$ & Другие \\
\hline $\begin{array}{c}\text { Америка } \\
\text { Соединенные Штаты }\end{array}$ & 100 & 0,7 & 13,8 & 4,9 & 78,4 & 2,2 \\
\hline Япония & 100 & 8,0 & 23,6 & 15,0 & 50,2 & 3,2 \\
\hline Германия & 100 & 4,5 & 30,2 & 12,5 & 45,0 & 7,8 \\
\hline Франция & 100 & 7,5 & 22,8 & 14,0 & 46,9 & 8,8 \\
\hline Великобритания & 100 & 2,1 & 24,2 & 14,9 & 48,0 & 10,8 \\
\hline Узбекистан & 100 & 25,5 & 13,2 & 12,1 & 12,7 & 36,5 \\
\hline
\end{tabular}

Сегодня в сфере услуг создается все больше и больше рабочих мест, и этот сектор развивается как новый сектор экономики. В результате доля промышленности и сельского хозяйства в ВВП сокращается, а вместо этого растет доля услуг. Однако это не означает, что экономики развитых стран будут «деиндустриализированы».

Даже если доля промышленности в ВВП снизится, ее абсолютное значение на душу населения увеличится, а увеличение числа работников в сфере услуг будет лишь свидетельствовать о деиндустриализации рабочей силы.

Снижение доли промышленности и сельского хозяйства в ВВП в развитых странах свидетельствует об эффективности этих секторов, а это означает, что затраты в этой сфере будут сокращены.

Теперь проанализируем формирование меняющейся профессиональной структуры занятости в странахлидерах. Перед этим следует отметить, что на протяжении всей истории «трудовые навыки» становились более важными, чем понятие «рабочая сила». Также следует отметить, что в развитых странах существует уникальная профессиональная структура в сфере занятости. В-третьих, повышение квалификации рабочей силы приведет к сокращению числа занятых и, следовательно, к структурным изменениям.

Специализация менеджеров, квалифицированных специалистов и технических специалистов набирает популярность практически во всех странах. С конца XX века основное внимание уделяется проблемам «стратегического» управления производством (автоматизация новых технологий), реструктуризации организационных структур, предпринимательства, управления человеческими ресурсами и формирования кооперативов. В то же время существуют межстрановые различия в оценке престижа и востребованности отдельных профессий. (Таблица 2)

Таблица 2.

Сравнительный анализ самых престижных и высокооплачиваемых профессий в США и России ${ }^{2}$

\begin{tabular}{|c|c|}
\hline Соединенные Штаты & Россия \\
\hline \multicolumn{2}{|c|}{ Самые престижные профессии } \\
\hline
\end{tabular}

1 Манба: ILO. Year Book of Labour Statistics.-Geneva, 2017. Page: 240-243, 274-279, 340-341, 336-339, 386-389. Ўзбекистон Иқтисодиёти. 2018-йил, 8-сони 28-бет.

${ }^{2}$ Манба: Ряэанцев СВ. Мировой рынок труда и международная миграция: Учебное пособие. - Москва; ЗАО «Издательство «Экономика», 2018. С. - 34. 


\begin{tabular}{|c|c|}
\hline 1. Пожарные (57\%) & 1. Юрист (28\%) \\
\hline 2. Ученый (56\%) & 2. Экономист \\
\hline 3. Врач $(53 \%)$ & 3. Финансист \\
\hline 4. Медсестра и учитель (52\%) & 4. Менеджер \\
\hline 5. Военные и полиция (46\%) & 5. Бизнесмен \\
\hline 6. Фермер (41\%) & 6. Врач \\
\hline 7. Священник (40\%) & 7. Госслужащий \\
\hline 8. Инженер (40\%) & 8. Программист \\
\hline 9. Конгрессмен (28\%) & 9. Бухгалтер \\
\hline 10. Журналистика (18\%) & 10. сотрудник шоу-бизнеса \\
\hline $\begin{array}{c}11 . \text { Актеры (15\%) } \\
\text { Менее известные профессии включают риэлторов, биржевых маклеров и } \\
\text { банкиров. }(6 \%) \\
\end{array}$ & \\
\hline \multicolumn{2}{|l|}{ Самые высокооплачиваемые профессии } \\
\hline Анестезиологи (193000 долларов в год) & 1. Банкир \\
\hline 2. Хирурги (191,4 тысячи долларов в год) & 2. Бизнесмен \\
\hline 3. Ортодонты (185,3 тыс. Долларов в год) & 3. Юрист \\
\hline 4. Стоматологи & 4. Директор (менеджер) \\
\hline \multirow[t]{2}{*}{ 5. Врачи по контролю над рождаемостью } & 5. Госслужащий \\
\hline & 6. Экономист (финансист) \\
\hline 10. Топ-менеджер (151,4 тыс. \$ В год) & 7. Врач \\
\hline 11. Пилот (148,6 тыс. Долларов в год) & 8. Бухгалтер \\
\hline $\begin{array}{c}\text { Двадцатые заканчиваются отраслевыми менеджерами и юристами. На 25-м } \\
\text { месте финансовые менеджеры, которые зарабатывают \$ 106,2 тысячи в год. } \\
\text { расходы }\end{array}$ & 9. Программист \\
\hline & 10. Сотрудник шоу-бизнеса \\
\hline
\end{tabular}

Как видно из таблицы, самые высокооплачиваемые профессии в США так или иначе связаны с формированием человеческого потенциала. В России все наоборот. По словам Head Hunter, на международном рынке труда будут доминировать инженеры, ИТ-специалисты и разработчики компьютерного программного обеспечения, профессионалы в области нанотехнологий, профессионалы в области электроники и биотехнологий, маркетологи, специалисты в сфере услуг, логистики и т. Д., Специалисты в области экологии, медицины, химии будут в спросе.

В 2018 году только каждый пятый выпускник по своей специальности сможет найти работу в России. Среди многих развитых стран Япония значительно улучшила свою специализацию. Здесь доля руководителей (старше 20 лет) увеличилась на 46,2\%, а количество квалифицированных рабочих, а также технических работников увеличилось на 91,4\%. В Великобритании количество менеджеров также увеличилось на $96,3 \%$, но количество специалистов и техников уменьшилось на $5,2 \%$. Таким образом, мы можем наблюдать разные темпы роста занятости в группе менеджеров, квалифицированных специалистов и технических работников. Основная причина этого в том, что исходная ситуация в этих странах иная. Однако в целом доля этой группы занятий в общей занятости растет во всех странах. 
Повышение экономической эффективности, увеличение количества и разнообразия потребительских товаров повысит уровень жизни людей и обогатит их. Это связано с ростом социально ориентированной национальной экономики.

Таким образом, основываясь на нашем исследовании, мы можем сделать вывод, что производство в каждом регионе, в обществе основано на постоянном повышении производительности труда в каждом секторе. Благосостояние общества может увеличиваться только в том случае, если население будет эффективно трудоустроено.

Анализ результатов опроса показал, что уровень безработицы среди экономически активного населения составил 9,1\%, что на $0,2 \%$ ниже аналогичного периода 2018 года. Самый высокий уровень безработицы зарегистрирован в Кашкадарьинской, Сырдарьинской и Ферганской областях - 9,4\%, а самый низкий - в Ташкенте $(7,7 \%)$.

По данным Госкомстата Республики Узбекистан, численность нуждающихся в трудоустройстве составляет 1342,6 тыс. Человек, уровень безработицы среди молодежи (до 30 лет) составляет 15,1\%, среди лиц в возрасте от 15 до 25 лет - 16, 8 процентов, среди женщин - 12,7 процента.

Количество трудовых ресурсов составило 18964000 человек, что на 1\% больше, чем в январе-июне 2018 года. Численность экономически активного населения увеличилась на 181,5 тыс. Или $1,2 \%$ по сравнению с аналогичным периодом 2018 года. Экономически неактивное население составило 4 213,0 (рост на 0,1\%), при этом на 4,4\% увеличилось количество женщин, находящихся в декретном отпуске, декретном отпуске или уходе за детьми в возрасте до 2 лет. Следует отметить, что количество добровольно потерявших работу резко снизилось с 805,6 тыс. До 734 тыс. (8,9\%), что означает рост трудовой и предпринимательской активности.

В системе занятости наблюдается рост числа людей, занятых в формальном секторе экономики, и сокращение занятости в неформальном секторе. В частности, общая численность занятых в экономике достигла 13 408,4 тыс. Человек, что на 1,4\% больше, чем в январе-июне 2018 года. В то же время численность занятых в официальном секторе экономики впервые в истории Узбекистана увеличилась на 326,3 тысячи или 6,2\% до 5 593,6 тысячи. С другой стороны, количество людей, занятых в неформальном секторе, уменьшилось на 137,7 тыс. Человек, или $1,7 \%$, до 7814,8 тыс. Человек. Это прямой результат неформальной деловой активности и мер по легализации рабочих мест.

Опрос также показал, что количество выехавших за границу в целях трудовой миграции уменьшилось на 1,9\% по сравнению с соответствующим периодом 2018 года - с 2644,1 тысячи до 2594,1 тысячи.

В январе-июне текущего года за помощью в трудоустройстве в районные и городские центры занятости обратилось 404569 человек, в том числе 138173 человека в возрасте от 16 до 30 лет. Из подавших заявления 167 713 человек были трудоустроены, 139679 участвовали в общественных работах, 10085 были направлены на переподготовку и 31938 получили пособие по безработице.

Исходя из вышесказанного, существует ряд проблем в качественном формировании структуры занятости и повышении ее эффективности в стране. На наш взгляд, это следующие проблемы:

1. Отсутствие квалифицированного персонала. Углубляющееся разделение труда в экономике закладывает основу для появления новых современных отраслей. В результате на рынке труда растет спрос на квалифицированные кадры современных профессий.

В последние 3-4 года наблюдается рост количества квалифицированных рабочих в центрах занятости и социальной защиты, увеличение занятости специалистов с высшим и средним специальным образованием. Однако на рынке труда республики обеспеченность высокообразованными и квалифицированными кадрами составляет 7-8\%, в отдельных случаях 6-7\%.

2. Структурная безработица. Изменения технологических и имущественных отношений в различных отраслях экономики приводят к увеличению структурной безработицы. Однако уровень структурной безработицы в последние годы снижается в результате создания новых рабочих мест в различных секторах экономики.

3. Несоответствие между составом квалифицированных кадров, необходимых для секторов экономики, и подготовкой и ориентацией образовательных учреждений. Качество подготовки квалифицированных кадров в системе образования и центрах должно быть таким, как уровень трудоустройства выпускников.

4.Высокий уровень безработицы, увеличивающий средний период безработицы до 6-7 месяцев. В результате увеличение доли непроизводительного труда в производстве приводит к потере десятков тысяч рабочих часов в день.

5. Высокий уровень безработицы: отсутствие информации о вакансиях; требование работодателем дублирующих документов, не предусмотренных законодательством; продление методов подбора персонала; у большинства одинаковая специализация; в связи с длительностью переподготовки и другими причинами.

6. Высокая текучесть кадров.Основными причинами высокой текучести кадров на предприятиях являются: отсутствие привязки заработной платы к конечным результатам деятельности предприятия; рост цен на билеты на автотранспорт; сокращение штатов; ухудшение условий труда на рабочем месте; нарушение работодателем трудового законодательства и др. 
7. Сложность получения соискателями информации о конкурсах вакансий, конфиденциальность информации о вакансиях со стороны работодателей.

На наш взгляд, для решения этих проблем целесообразно принять следующие меры:

- Осуществление опережающего развития производственной инфраструктуры малого бизнеса и частного предпринимательства в сельской местности.

- Отделы предпринимательства.

- Ускоренное развитие знаний и трудоемких услуг в сельской местности, переход к интенсивным технологиям, создание малых предприятий и частного предпринимательства, обеспечивающих необходимую мобильность населения, играют важную роль в повышении качества занятости за счет создания предпринимательской среды.

В целом, исходя из вышеизложенного, мы полагаем, что текущие тенденции улучшения структуры занятости, следующие:

- увеличение количества субъектов хозяйствования;

- изменение количества рабочих мест в различных секторах экономики в связи со структурными изменениями;

- наличие рабочих мест с равным общим образованием и профессиональным образованием;

- Признание потребности в дополнительном образовании со стороны работающих;

- изменение отношения к радикальным реформам в экономике.

В заключение, в Узбекистане проводится значительная работа по улучшению структуры занятости, но в то же время ясно, что еще многое предстоит сделать для улучшения качества занятости. Таким образом, реализация вышеперечисленных предложений повысит качество трудоустройства.

\section{ИСПОЛЬЗОВАННАЯ ЛИТЕРАТУРА}

1.Абулкосимов Х.Р. Человеческий фактор в экономике: его формирование, функционирование и активация. Монография. - Т.: Академия, 2006. - 346 с.

2. Гонорская А.В. Обеспечение качества трудовых ресурсов Республики Узбекистан с использованием потенциала негосударственных некоммерческих организаций // Автореф. дисс. канд. экон. наук. - Т.: 2002.-С.13. - C. 88.

3.Зокирова Н.К. Социально-трудовые отношения: международный и национальные аспекты. - Т .: Фан, 2008.

4. Мирсаидов Д. Развитие семейного бизнеса в национальной экономике как новое направление занятости. // Сборник тезисов Республиканской студенческой научно-практической конференции. 6 апреля 2013 г.Часть 2

5.Мирсаидов Д. Направления совершенствования структуры занятости населения в экономике //Сборник тезисов Республиканской студенческой научно-практической конференции. 6 апреля 2013 г. Часть 2.

6. Данные Министерства труда и социальной защиты населения Республики Узбекистан. Ташкент: 2017-2020 гг.

7. Данные Государственного комитета по статистике Республики Узбекистан. Ташкент: 2018-2020.

8. Данные Торгово-промышленной палаты Республики Узбекистан.

9.http:// www.gov.uz

10.http://www.wto.org

11. http:// www.goldenpages.uz

12.http:// www.imce.ru

13.http:// www.lex.uz.

14.http:// www.mehnat.uz. 